\title{
THE EFFECT OF PLASMA PRETREATMENT ON THE MORPHOLOGY AND PROPERTIES OF HITUS COATINGS
}

\author{
Lenka Kvetková, Petra Hviščová, Dávid Medved', František Lofaj
}

\begin{abstract}
WC coatings prepared by High Target Utilization Sputtering (HITUS), a relatively new technology, were deposited on three types of substrates. These were silicon (111), steel (100Cr6), and ceramic (WC-Co). The influence of RF plasma power pretreatment on final properties of WC coatings was investigated with two interlayer materials for bonding. The morphology, roughness, and mechanical properties of coatings were studied. The relation between plasma RF power and roughness was found. No significant change in mechanical properties was detected with change in plasma RF power. The dependence of nanohardness and scratch behavior on HITUS WC coatings was investigated.
\end{abstract}

Keywords: WC coatings, High target utilization sputtering, nanohardness.

\section{INTRODUCTION}

Transition metal carbides are frequently used in industry due to their outstanding properties such as high hardness, wear resistance, chemical and thermal stability and thermal conductivity. WC is a well-known material due to its high hardness (24-30 GPa), melting temperature $\left(2870{ }^{\circ} \mathrm{C}\right)$, Young's Modulus (400-670 GPa) and chemical inertness. It was considered as an alternative to diamond when it was first synthesized in the early 19th century. There are some applications in microelectronic circuits and some aircraft components. As for tribological applications, WC is generally used as single layer or in multilayer coatings as a reinforcement phase or oxidation resistant layer. An overview of the related literature exhibits that WC coatings are generally synthesized through a sputter deposition method using either $\mathrm{W}$ or $\mathrm{WC}$ targets with the help of a carbonaceous gas such as methane, acetylene, benzene [1-8].

High Target Utilization Sputtering (HITUS) is a relatively new sputter deposition method with an independent plasma source driven by a RF power supply separated from the deposition chamber. It offers higher plasma densities, possibilities for an increase of the level of ionization of the sputtered material and significant reduction of negative effects accompanying reactive sputtering related to target poisoning. The Ar plasma is extracted into the chamber by a "launch" electromagnet. Due to the small plasma energy of Ar ions $(\sim 10 \mathrm{eV})$, no sputtering occurs at this stage and plasma is just flooding the chamber. The magnetic field of an electromagnet underneath the target transforms the plasma into a beam directed onto the target to achieve ion energy necessary for target sputtering. Another independent RF power supply is used to bias the target. Thus, an independent control of plasma density and sputtering ion energy is possible. This results in reduced ion bombardment of the substrate and its temperature, higher deposition rates, densities and reduced intrinsic stresses with over $90 \%$ utilization of target surface.

Lenka Kvetková, Petra Hviščová, Dávid Medved', František Lofaj: Slovak Academy of Sciences, Institute of Materials Research, Watsonova 47, Košice 040 01, Slovakia 
The application of HITUS to the tungsten carbide based coating systems for engineering applications began in 2014. In the HITUS WC coatings deposited on steel substrates with different additions of acetylene, hardness up to $34 \mathrm{GPa}$ was achieved. The structure and the final mechanical properties of WC coatings were found to be influenced not only by acetylene but also by the deposition parameters, RF plasma power, substrate type and even by the pretreatment of the substrate. These factors of HITUS WC coatings had not been investigated up to now.

The surface roughness is an important parameter influencing contact stresses, especially at the coating-substrate interface. This was first shown by Sainsot et al [9], who also concluded that in hard coatings with thicknesses less than $15 \mu \mathrm{m}$ on softer substrates, the maximum von Mises stresses, both in the coating and in the substrate, will be located just at their interface. This clearly confirms the importance of analyzing the stresses at the coating-substrate interface and comparing them to the coating adhesion strength. In rolling contact fatigue situations (e.g. rolling bearings), the surface roughness will result in smallscale contact stress spikes that initiate cracks and result in failure [10-12].

The surface pre-treatment in a vacuum chamber is an important procedure which improves the cohesion of coating to substrates by activation of substrate bonds. Usually it is performed prior to the process in inert Ar plasma with high bias voltage applied to the substrate. The remote plasma source of HITUS allows independent control of ion density (set by the RF power) and ion energy (set by the bias). The aim of this contribution is to study the influence of RP plasma power pretreatment on roughness, adhesion and mechanical properties of WC coatings ( $\mathrm{Cr}$ and Ti interlayers) deposited on three substrates.

Besides adhesion of the coating to the substrate, the hardness and scratch testing are the substantial parameters for its practical applications. This work also deals with cracking in hard brittle WC coating/steel substrate during nanoindentation and scratch testing.

\section{EXPERIMENTAL DEPOSITION SYSTEM AND PROCEDURE}

The tungsten carbide (WC) tribological coatings were deposited on three different types of substrates in PQL 500 (Plasma Quest Ltd., UK) HITUS deposition system [15]. The details of deposition were described in [16]. After reaching the pressure $2.6 \times 10^{-6} \mathrm{mBar}$ prior to the deposition, the substrate was subjected to plasma cleaning using different RF powers for $30 \mathrm{~min}$. Then, approximately $150 \mathrm{~nm}$ thick interlayer was deposited to improve the WC coating adhesion to the substrate from $\mathrm{Ti}$, and $\mathrm{Cr}$ targets, respectively. The final WC coatings were deposited from stoichiometric WC target at working pressure of $5 \times 10^{-3}$ $\mathrm{mBar}$ and deposition time of $100 \mathrm{~min}$ in pure Ar atmosphere. The RF power on plasma source was $2.5 \mathrm{~kW}$ and power on target was $500 \mathrm{~W}$ and additional power of $100 \mathrm{~W}$ was applied to the substrates. The technological parameter which changed was RF power of plasma pre-cleaning and the element ( $\mathrm{Ti}$ or $\mathrm{Cr}$ ) of interlayer-bonding coating. Based on previous research, the cleaning RF power of $1000 \mathrm{~W}$ was selected and the coating prepared with different bonding layer, $\mathrm{Ti}$ and $\mathrm{Cr}$. The WC coatings were prepared with the following values of plasma lance supply - PLS RF power of 800, 1000, 1200 and $1500 \mathrm{~W}$ with Cr interlayer.

As substrates bearing steel, bulk ceramics WC-Co and silicon wafers were selected. Steel 100Cr6 in the form of heat treated cylinders with $30 \mathrm{~mm}$ diameter, $3 \mathrm{~mm}$ thick, metallographically ground, polished to roughness about $R_{a}=15 \mathrm{~nm}$ was used. The hardness and modulus of steel prior to deposition was $\mathrm{H}_{\mathrm{IT}}=3.2 \mathrm{GPa}, \mathrm{E}_{\mathrm{IT}} 163 \mathrm{GPa}$. Bulk ceramics WC-Co discs were of $12 \mathrm{~mm}$ diameter and thickness $1 \mathrm{~mm}$. The surface was prepared in the same way as the steel one. Hardness and modulus of WC-Co was $21 \mathrm{GPa}$ 
and $530 \mathrm{GPa}$, respectively. Silicon wafer plate with rectangular shape and thickness of 0.5 $\mathrm{mm}$ in delivery state and roughness with hardness and modulus of $\mathrm{H}_{\mathrm{IT}}=13 \mathrm{GPa}$ and $\mathrm{E}_{\mathrm{IT}}=$ $178 \mathrm{GPa}$. All three substrates were placed in the chamber simultaneously.

The topography and roughness of deposited coatings was measured using a confocal microscope with interferometer (PluNeox, Sensofar, Spain) and selected coatings also with SEM (Auriga Comact Zeiss). The average of three measurements in the middle and two ends of specimen was used. The instrumented hardness $\mathrm{H}_{\mathrm{IT}}$ and modulus $\mathrm{E}_{\mathrm{IT}}$ of coatings was measured using the nanoindenter (G200, Agilent). The continuous stiffness measurement mode with amplitude of $2 \mathrm{~nm}$, frequency of $45 \mathrm{~Hz}$ and strain rate of $0.005 \mathrm{~s}^{-1}$ and indentation depth of $1 \mu \mathrm{m}$ was used to evaluate the properties across the thickness of the coating. The resulted $\mathrm{H}_{\mathrm{IT}}$ and $\mathrm{E}_{\mathrm{IT}}$ values were determined in the 1/10 of indentation depth. Scratch tester Bruker UMT 2M in progressive load mode with scratching distance of $3 \mathrm{~mm}$ with Rockwell $120^{\circ}$ diamond tip supported with acoustic emission was used. Scratch tests were performed with the same nanoindenter using a maximum force of $500 \mathrm{mN}$, sliding rate $100 \mu \mathrm{ms}^{-1}$ and length of $1000 \mu \mathrm{m}$. Two scratches were made on each test sample. The scratch paths and cross sections were observed using optical, confocal and scanning electron microscopy.

\section{RESULTS AND DISCUSSION}

\section{Roughness and topography}

Fig. 1 compares the SEM topographies of the reference WC coatings on three different substrates. The surface of the coating on $\mathrm{Si}$ substrate contained small, homogeneously distributed undulations. The topography of the coating on steel substrate differed significantly (Fig. 1b). Grain-like features in $1 \mu \mathrm{m}$ size range were sometimes present and they sometimes contained rounded particles. The surface in the case of WC-Co substrate (Fig. 1c) reminded strongly of overetched fine-grained microstructure of WC-Co hardmetals with different height levels for WC grains and Co binder, resulting in a relatively rough surface.

a)

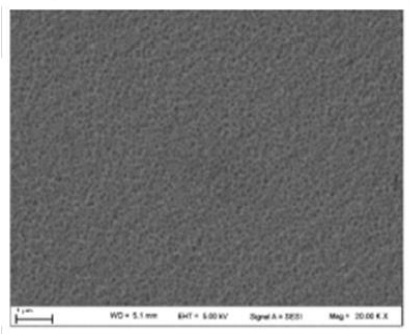

Fig. 1. Topography of HITUS WC b)

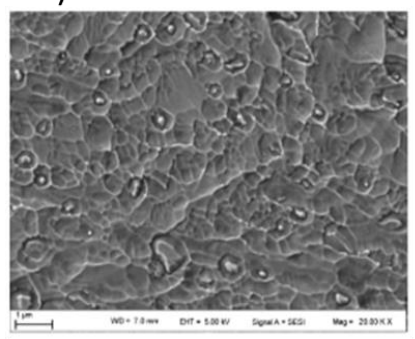

c)

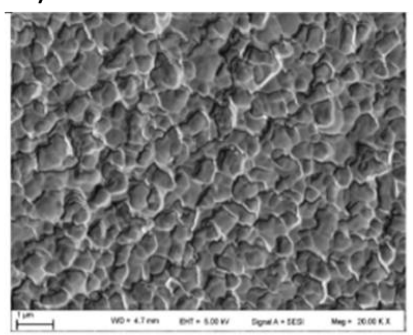
steel; c) WC-Co substrate.

All substrates, except the silicon, were prepared before deposition metallographically, ground and polished to roughness about $R_{a}=15 \mathrm{~nm}$, Figs. 2, 4. Si wafers were used in the as-delivered state. After the plasma pre-treatment, the $\mathrm{Ti}$ and $\mathrm{Cr}$ coatings were deposited. The thickness of $\mathrm{Cr}$ and $\mathrm{Ti}$ coatings were $\sim 150 \mathrm{~nm}[14,15]$ and the roughness $\mathrm{R}_{\mathrm{a}}$ of $\mathrm{Ti}$ and $\mathrm{Cr}$ was on the Si substrate 25 and $15 \mathrm{~nm}$, respectively. After the deposition of WC coating on the Si substrate, with thickness of $1.2 \mu \mathrm{m}[14,15]$, the roughness decreases to that of delivery state $\left(R_{a}=15 \mathrm{~nm}\right)$. In the case of WC-Co substrates 
the roughness after grinding and polishing was approximately the same as for $\mathrm{Si}$. The roughness of WC-Co increased above $5 \mathrm{~nm}$ after plasma pre-treatment. The same increase of roughness $\sim 5 \mathrm{~nm}$ was noticed after the deposition of Ti coating. More significant increase of roughness was measured on deposited Cr coating, Fig. 2. The difference in roughness of WC coatings of both interlayers is in the scatter range. Similar results of roughness were measured on steel substrates. The roughness after the plasma pre-treatment slightly decreases and after the deposition of $\mathrm{Ti}$ or $\mathrm{Cr}$ coatings markedly increases. The roughness of WC coatings was also higher. The measured $\mathrm{R}_{\mathrm{a}}$ values are in good agreement with surface appearance, Fig. 4a. After deposition of interlayer $\mathrm{Cr}$ or $\mathrm{Ti}$, the surfaces have the appearance of grain-like microstructure. This structure is copied by WC coating too. The influence of applied plasma pre-treatment power on final morphology and roughness of WC coatings is summarized in Figs.3, 4b. The most significant difference in measured values of $\mathrm{R}_{\mathrm{a}}$ was found at RF power of $1000 \mathrm{~W}$, where, in the case of steel and WC-Co substrates, increase of $\mathrm{R}_{\mathrm{a}}$ is caused, and in the case of $\mathrm{Si}$, it causes a decrease of roughness. The resulted surfaces are shown in Fig. $4 b$. Similar roughness $R_{a}$ of 10-70 nm was measured by [17], after the deposition of a WC coating on steel substrates with different thicknesses.

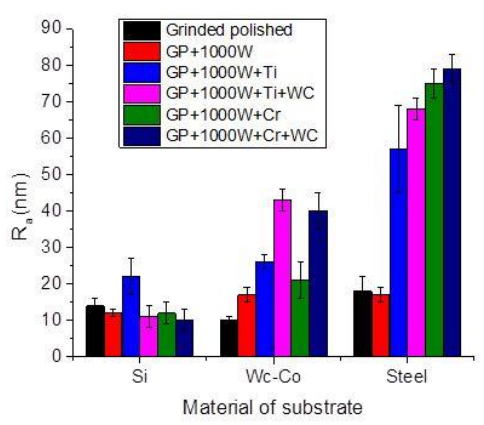

$\overline{\text { Fig. 2. Measured roughness of investigated }}$ materials, interlayers and final WC coatings at same RF plasma power pretreatment

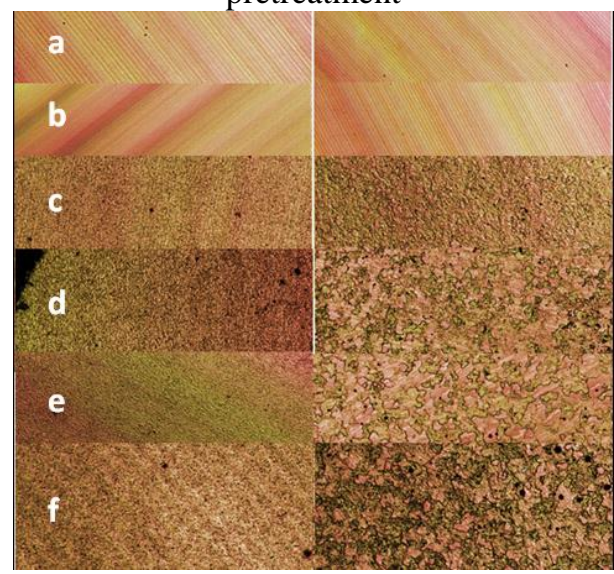

Fig. 4a. Confocal microscopy figures of WC coatings deposited on WC-Co (left)

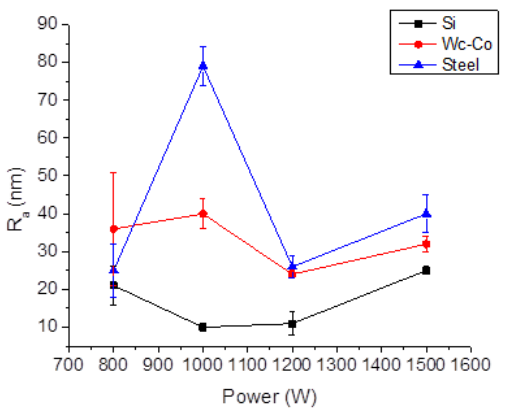

Fig. 3. Dependence of roughness of the WC coating (with $\mathrm{Cr}$ interlayer) on $\mathrm{RF}$ plasma pre-treatment power

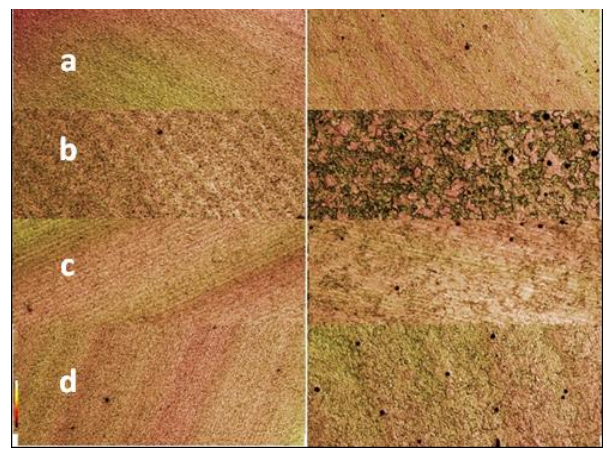

Fig. 4b. Confocal microscopy figures of WC coatings deposited on WC-Co (left) 
and steel (right) substrates, a)ground and polished surface, b) plasma pretreated $1000 \mathrm{~W}, \mathrm{c}) \mathrm{Ti}$ coating, d) WC coating with $\mathrm{Ti}$ interlayer, e) $\mathrm{Cr}$ coating, WC with $\mathrm{Cr}$ interlayer and steel (right) substrates with different plasma RF power - a) $800 \mathrm{~W}$, b) $1000 \mathrm{~W}$

c) 1200 and d) $1500 \mathrm{~W}$.

\section{Scratch test}

Three scratches were performed on each of coatings with progressing load. The distance from start to first appearance of crack was measured and based on it the critical load was evaluated. The average values are in Fig. 5. The adhesion of WC coating to steel is in the range of scatter for all plasma treating power; on Si there is a decrease of adhesion with increasing power; on WC-Co substrate at $1000 \mathrm{~W}$ there is a decrease of adhesion, which may have been caused by a higher roughness of the coating. The values of Fc1, in all coatings in comparison to other works, are relatively small [18]. On the other hand, the chipping of coating at $3 \mathrm{~mm}$ distance from the beginning and maximal load of $40 \mathrm{~N}$ was not monitored.

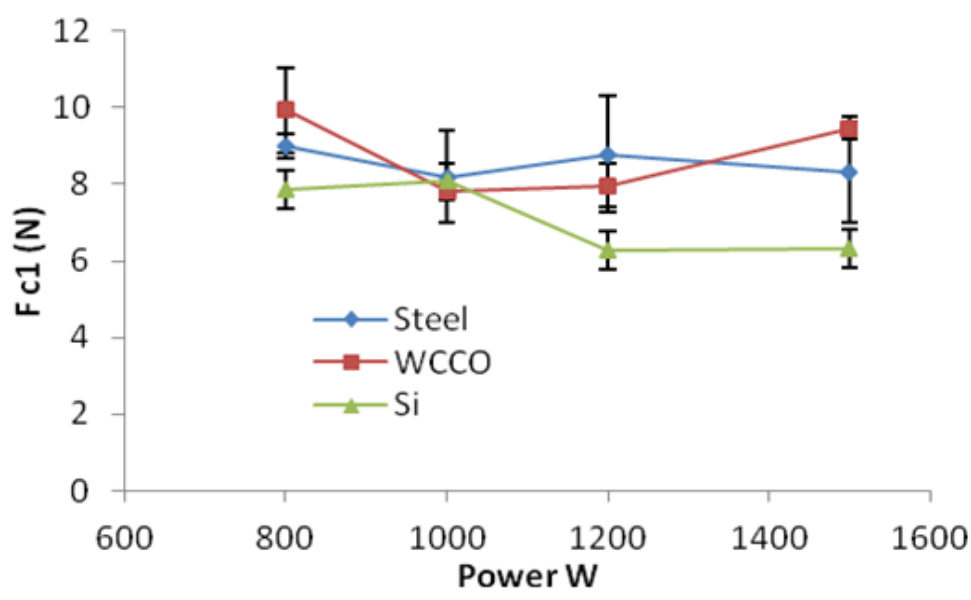

Fig. 5. The dependence of adhesion critical loads Fc1 of WC coatings on power of RF plasma pretreatment measured by the scratch test.

In the WC coatings prepared on WC-Co substrate, massive delamination occurred. In WC coatings, the compressive residual stresses caused an approximately linear increase of the measured nanohardness [14]. However, when the adhesion was not sufficient, compressive stresses above several GPa resulted in extensive cracking and complete delamination.

Fig. 6 shows the penetration depth and load along two scratches in the WC coatings on the steel substrate and WC-Co substrate. The first slight oscillations of the curve appeared at around $50 \mu \mathrm{m}$ distance when the first damage of the coating. It corresponded to Lc1. 


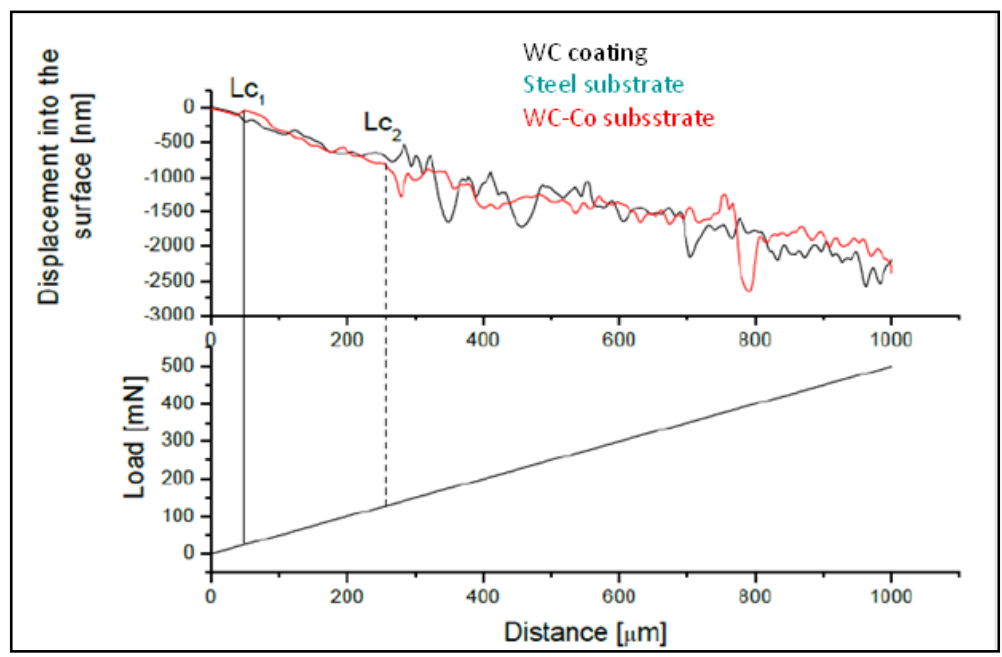

Fig. 6. The dependence of penetration depth and load along two scratches .

During the scratch-test, failure of the coatings begins with either semi-circular cracking or with side-flaking, Fig. 7. The failure of WC coating prepared on steel substrate began with the side-flaking on both sides of the scratch, Fig. 7a. The same mechanism, however, has been determined for the failure initiation in the case of the WC film grown on WC-Co substrate, Fig. 7b. This film had slightly lower adhesion and the critical load was $100 \mathrm{mN}$.

a) WC on steel substrate

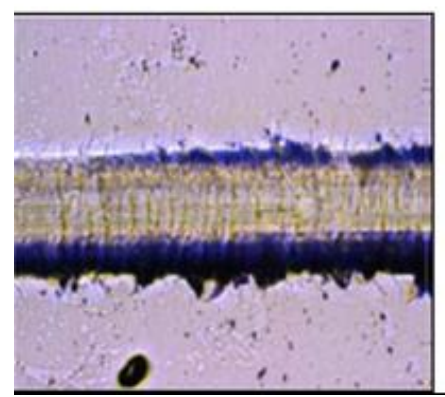

b) on WC-Co substrate

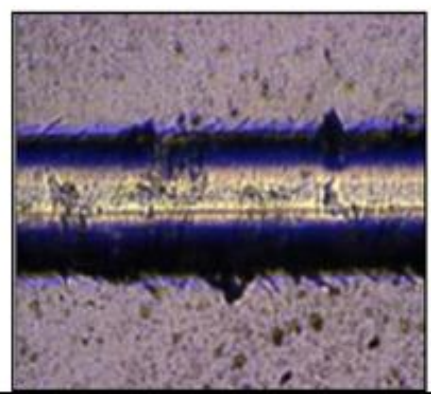

Fig. 7. Micrographs showing scratches made on WC films on: steel substrate a) and WC-Co substrate b).

\section{Hardness and modulus}

The comparison of depth profile of the reference WC coating on different substrates, Si wafer, WC-Co, and 100Cr6 steel are presented in Fig. 8. The peak values were evaluated based on the thumb rule of $1 / 10$ of coating thickness and are present in Tab. 1. The average hardness of the coating, HIT, was around $24 \pm 3 \mathrm{GPa}$. The best-defined and the highest hardness peak in the depth range of 150-200 nm were obtained on a steel substrate, Fig. 8c, using 1500 and $1200 \mathrm{~W}$ of PLS RF power, Tab. 1. 

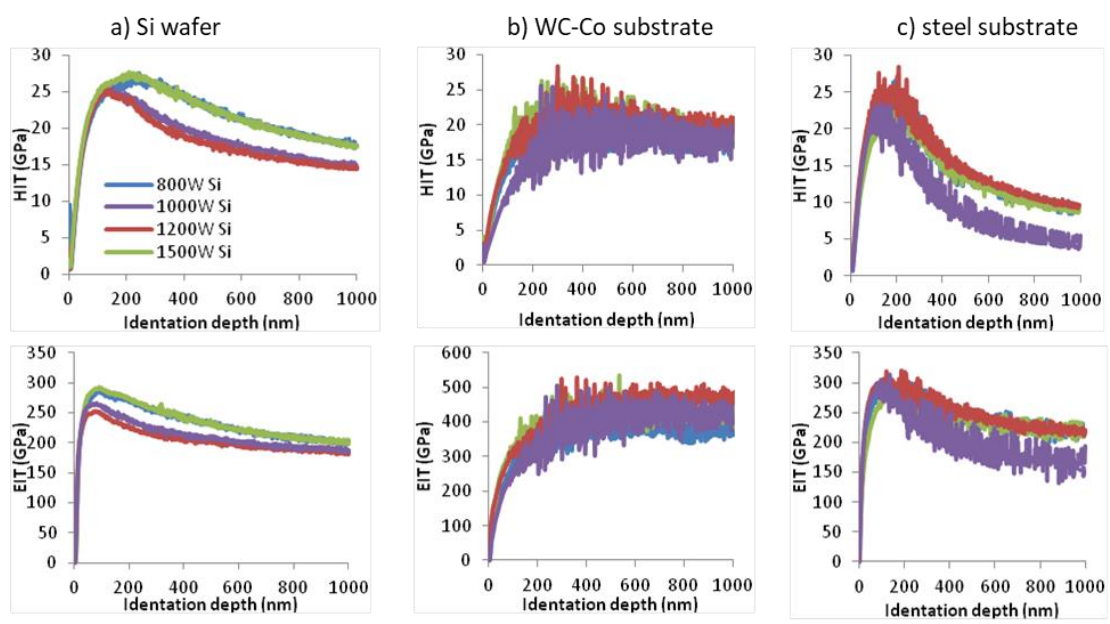

Fig. 8. Indentation hardness (HIT) and modulus (EIT) of WC coating with Cr interlayer on a) $\mathrm{Si}, \mathrm{b}) \mathrm{WC}-\mathrm{Co}, \mathrm{b}) 100 \mathrm{Cr} 6$ steel substrates with different plasma pretreatment RF power $(800,1000,1200,1500 \mathrm{~W})$

On a Si wafer and WC-Co substrate, the peaks of hardness depth profile were within the error bar range. The indentation moduli obtained on steel substrate and Si wafer, using $1500 \mathrm{~W}$ of PLS power, were mostly within the range 270-300 GPa, but indentation moduli on WC-Co substrate was slightly higher, $350 \mathrm{GPa}$. Thus, the studied substrates and PLS RF power resulted in a 3-4 GPa hardness difference, whereas the indentation moduli using WC-Co substrate were slightly higher. Nanoindentation hardness and modulus are strongly dependent on surface roughness, which is well visible in Fig. 8b on WC coating on the WC-Co substrate. There is no significant difference in indentation hardness and modulus measured on WC-Co coatings on all three substrates, except the WC-Co at 1500 $\mathrm{W}$ power.

Tab. 1. The average values of indentation hardness and modulus of WC coating with $\mathrm{Cr}$ interlayer deposited after the plasma treatment with different RF power

\begin{tabular}{|c|c|c|c|c|c|c|c|c|c|c|c|c|c|}
\hline Subst. & \multicolumn{4}{|c|}{ Si } & \multicolumn{4}{c|}{ WC-Co } & \multicolumn{4}{c|}{ Steel } \\
\hline Power & $\begin{array}{c}\mathbf{E}_{\text {IT }} \\
(\mathbf{C r})\end{array}$ & $\begin{array}{c}\mathbf{E}_{\text {IT }} \\
(\mathbf{T i})\end{array}$ & $\begin{array}{c}\mathbf{H}_{\text {IT }} \\
(\mathbf{C r})\end{array}$ & $\begin{array}{c}\mathbf{H}_{\text {IT }} \\
(\mathbf{T i})\end{array}$ & $\begin{array}{c}\mathbf{E}_{\text {IT }} \\
(\mathbf{C r})\end{array}$ & $\begin{array}{c}\mathbf{E}_{\text {IT }} \\
(\mathbf{T i})\end{array}$ & $\begin{array}{c}\mathbf{H}_{\text {IT }} \\
(\mathbf{C r})\end{array}$ & $\begin{array}{c}\mathbf{H}_{\text {IT }} \\
(\mathbf{T i})\end{array}$ & $\begin{array}{c}\mathbf{E}_{\text {IT }} \\
(\mathbf{C r})\end{array}$ & $\begin{array}{c}\mathbf{E}_{\text {IT }} \\
(\mathbf{T i})\end{array}$ & $\begin{array}{c}\mathbf{H}_{\text {IT }} \\
(\mathbf{C r})\end{array}$ & $\begin{array}{c}\mathbf{H}_{\text {IT }} \\
(\mathbf{T i})\end{array}$ \\
\hline $\mathbf{W}$ & \multicolumn{2}{|c|}{$\mathbf{G P a}$} & \multicolumn{2}{|c|}{$\mathbf{G P a}$} & \multicolumn{2}{|c|}{$\mathbf{G P a}$} & \multicolumn{2}{|c|}{$\mathbf{G P a}$} & \multicolumn{2}{c|}{$\mathbf{G P a}$} & \multicolumn{2}{c|}{$\mathbf{G P a}$} \\
\hline 800 & $300 \pm 7$ & $295 \pm 4$ & $26 \pm 1.1$ & $25 \pm 0.6$ & $293 \pm 53$ & $295 \pm 71$ & $20 \pm 2.7$ & $19 \pm 0.9$ & $286 \pm 34$ & $268 \pm 53$ & $25 \pm 4.4$ & $23 \pm 3.2$ \\
\hline 1000 & $275 \pm 5$ & $260 \pm 7$ & $25 \pm 0.9$ & $26 \pm 0.9$ & $300 \pm 89$ & $294 \pm 57$ & $22 \pm 4.6$ & $20 \pm 1.2$ & $295 \pm 29$ & $284 \pm 30$ & $23 \pm 3.5$ & $22 \pm 2.4$ \\
\hline 1200 & $265 \pm 3$ & $255 \pm 5$ & $25 \pm 0.5$ & $25 \pm 0.5$ & $295 \pm 81$ & $291 \pm 82$ & $24 \pm 4.9$ & $25 \pm 5.1$ & $293 \pm 34$ & $285 \pm 35$ & $25 \pm 4.2$ & $24 \pm 0.1$ \\
\hline 1500 & $295 \pm 3$ & $300 \pm 3$ & $27 \pm 0.6$ & $26 \pm 0.8$ & $350 \pm 68$ & $356 \pm 74$ & $25 \pm 4.5$ & $25 \pm 3.5$ & $277 \pm 19$ & $280 \pm 20$ & $23 \pm 2.3$ & $23 \pm 0.9$ \\
\hline
\end{tabular}




\section{CONCLUSIONS}

The following conclusions can be drawn from the study of influence of plasma launch system RF power on properties of coatings:

1. The influence of substrate interlayer $(\mathrm{Cr}, \mathrm{Ti})$ on roughness and topography of $\mathrm{WC}$ coatings:

The topography of $\mathrm{Cr}$ coating - on steel: grain-like structure appears, on WC-Co substrate it is similar, but finer structure. The roughness $\mathrm{R}_{\mathrm{a}}$ of $\mathrm{Cr}$ interlayer on $\mathrm{Si}$ substrate is $13 \mathrm{~nm}$, on WC-Co $21 \mathrm{~nm}$ and on steel $75 \mathrm{~nm}$. The grain like structure was also found in case of $\mathrm{Ti}$ coating, but is finer than for $\mathrm{Cr}$ coating. The roughness $R_{a}$ of Ti interlayer is on Si $12 \mathrm{~nm}$, on WC-Co $26 \mathrm{~nm}$, on steel $59 \mathrm{~nm}$. The roughness of WC with Cr interlayer is: on Si $8 \mathrm{~nm}$, on WC-Co $39 \mathrm{~nm}$, on steel $79 \mathrm{~nm}$, with Ti interlayer on Si $11 \mathrm{~nm}$, on WC-Co $42 \mathrm{~nm}$ and on steel $69 \mathrm{~nm}$.

Dependence on applied pre-treatment power: $1000 \mathrm{~W}$ was found to be the minimum/maximum (for $\mathrm{Si} / \mathrm{WC}-\mathrm{Co}$, steel) of measured coating roughness.

2. Adhesion of all WC coatings with $\mathrm{Ti}$ interlayer was not measured. Using $\mathrm{Cr}$ interlayer it was in the range of $10 \pm 3 \mathrm{~N}$.

3. There is no significant difference in indentation hardness and modulus measured on WC coatings on all three substrates. The hardness of coatings is $\mathrm{H}_{\mathrm{IT}}=24 \mathrm{GPa}$ and modulus $\mathrm{E}_{\mathrm{IT}}=270-300 \mathrm{GPa}$.

4. The results showed that the substrates affect mostly the coating topography, roughness, and nanohardness, whereas the composition and indentation moduli were not considerably affected by different types of substrate. Around $5 \mathrm{GPa}$ difference in the hardness of the WC coatings were obtained using $800 \mathrm{~W}, 1000 \mathrm{~W}, 1200 \mathrm{~W}$, and $1500 \mathrm{~W}$ of Plasma lance System RF power in HITUS.

\section{ACKNOWLEDGMENTS}

The support provided by the projects APVV-15-0168, APVV-17-0320, APVV17-0049 and VEGA 2/0017/19 are acknowledged. The equipment used in the work was acquired from the projects "Research Centre of Advanced Materials and Technologies for Recent and Future Applications" PROMATECH, ITMS: 26220220186 and Advancement and support of R\&D for "Centre for diagnostics and quality testing of materials"in the domains of the RIS3 SK specialization, ITMS2014: 313011W442, supported by the Operational Program Integrated Infrastructure financed through European Regional Development Fund.

\section{REFERENCES}

[1] Sun, YM., Lee, S., Lemonds, A., Engbrecht, E., Veldman, S., Lozano, J., White, J., Ekerdt, J., Emesh, I., Pfeifer, K.: Thin Solid Films, vol. 397, 2001, p.109.

[2] Savarimuthu, A., Taber, H., Megat, I.: J. Therm. Spray Technol., vol. 10, 2001, p. 502.

[3] Rincon, C., Zambrano, G., Carvajal, A., Prieto, P.: Surf. Coat. Technol., vol. 148, 2001, p.277.

[4] Voevodin, AA., O’Neill, JP., Prasad, SV., Zabinski, JS.: J. Vac. Sci. Technol. A, vol. 17, 1999, p. 986.

[5] Abdelouahdi, K., Sant, C., Miserque, F., Aubert, P., Zheng, Y., Legrand Buscema, C., Perrière, J.: J. Phys. Condens. Matter, vol. 18, 2006, p. 1913.

[6] Czyzniewski, A.: Thin Solid Films, vol. 433, 2003, p. 180.

[7] Radić, N., Gržeta, B., Milat, O., Ivkov, J., Stubičar, M.: Thin Solid Films, vol. 320, 1998, p. 192.

[8] Palmquist, JP., Czigany, Z., Odén, M., Neidhart, J., Hultman, L., Jansson, U.: Thin 
Solid Films, vol. 444, 2003, p. 29.

[9] Sainsot, P., Leroy, J.M., Villechaise, B.: Mechanics of Coatings, Elsevier, 1990, p. 151.

[10] Polonsky IA., Chang, TP., Keer LM., Sproul WD.: Wear, vol. 208, 1997, p. 204.

[11] Nélias, D., Dumont, M.L., Champiot, F., Vincent, A., Girodin, D., Fougères, R., Flamand L.: J. Tribol., Trans. ASME, vol. 121, 1999, p. 240.

[12] Bhusan, B., Holmberg, K., Matthews, A.: Modern tribology handbook, Materials Coatings, and Industrial Applications, CRC Press LLC, 2001.

[13] Van Essen, P., Hoy, R., Kamminga, JD., Ehiasarian, AP., Janssen, GCAM.: Surface and Coatings Technology, vol. 200, 2006, p. 3496

[14] ISO 20502: 2005, Fine ceramics (advanced ceramics, advanced technical ceramics) Determination of adhesion of ceramic coatings by scratch testing.

[15] Lofaj, F., Kvetková, L., Hviščová, P., Gregor, M., Ferdinandy, M.: J. Eur. Ceram Soc. vol. 36, 2016, p. 3029.

[16] Lofaj, F., Hviščová, P., Zubko, P., Németh, D., Kabátová M.: Int. J. Refract. Hard. Met., vol. 80, 2019, p. 305.

[17] Podgornik, B., Wänstrand, O.: Materials Characterization, vol. 55, is. 3, 2005, p. 173.

[18] Drábik, M., Ballo, V., Truchlý, M., Frkáň, J., Roch, T., Kvetková, L., Satrapinksy, L., Kúš, P.: Surf. Coat. Technol., vol. 293, 2016, p. 2. 